\title{
Climate Change Increased The Compound Extreme Precipitation-Flood Events In A Representative Watershed of The Yangtze River Delta, China
}

\section{Yuxiu He}

Nanjing University

Qiang Wang ( $\nabla$ wqianghy@nju.edu.cn )

Nanjing University https://orcid.org/0000-0002-7941-880X

\section{Youpeng $\mathrm{Xu}$}

Nanjing University

\section{Ziyi Li}

Nanjing University

Jia Yuan

Nanjing University

Miao Lu

Nanjing University

Zhixin Lin

Nanjing University

\section{Research Article}

Keywords: Climate change, Bivariate frequency analysis, Copula-based framework, Extreme precipitation and flood events, Yangtze River Delta

Posted Date: December 2nd, 2021

DOl: https://doi.org/10.21203/rs.3.rs-1101769/v1

License: (c) (i) This work is licensed under a Creative Commons Attribution 4.0 International License. Read Full License

Version of Record: A version of this preprint was published at Stochastic Environmental Research and Risk Assessment on April 25th, 2022. See the published version at https://doi.org/10.1007/s00477-022-02229-8. 


\section{Abstract}

A compound perspective on hydrological extreme events is of paramount significance as it may lead to damages with larger losses. In this study, an integrated framework, based on downscaled climate variables and hydrological model, i.e. the Soil and Water Assessment Tool, was applied to generate extreme precipitation (Rx1day) and extreme streamflow (Sx1day) series under historical and future climate conditions. Then the potential impacts of climate change for univariate and bivariate joint frequency of extreme precipitation and flood in Xitiaoxi River Basin (XRB), a representative watershed of the Yangtze River Delta, is detected. The compound risk of extreme precipitation and flood under different levels of joint return period for historical and projected periods are estimated by copula-based two-dimensional approaches. Major findings can be summarized: (1) The Rx1day and Sx1day under future scenarios increased by $-0.4 \sim 11.7 \%$ and $0.7 \sim 20.4 \%$, respectively, compared to historical period based on univariate frequency analysis, indicating the increasing magnitude of the flood in the future. (2) Climate change with different emission scenarios all have a driving effect on the rising coactivity of extreme precipitation and flood under compound flooding frequency analysis. In addition, the enhancement of climate change to extreme events is more apparent for extremes with higher return period and under the periods of 2080s. (3) Moreover, the flood frequency designs are deduced by bivariate joint distribution are safer than that by univariate distribution. This study may provide actionable insights to formulate the planning scheme of flood control and disaster reduction under the changing environment.

\section{Introduction}

Global precipitation characteristics and flood situations are expected to undergo significant changes as a consequence of global climate change including increasing temperatures and varying precipitation patterns projected for the future climate (IPCC, 2014). The incessant increase in magnitude and frequency of weather extremes (Yang et al., 2019; Blöschl et al., 2019; Vormoor et al., 2015), and uncertainties under climatic change scenarios may cause extremely severe disasters (Stott, 2016; Chen et al., 2018; Swain et al., 2020; Hao and Singh, 2020). For instance, extreme hydrological events are becoming one of the most serious natural disasters in densely populated regions, such as the Yangtze River Delta, the most developed region of China (Han et al., 2015; Jiang et al., 2020; Wang et al., 2016). Accurate detection of the response in hydroclimatic extreme to changing environments has, therefore, become an urgent and difficult issue of study for disaster-causing process in critical watersheds as well as its flood protection (Garrote et al., 2016; Lin et al., 2021).

Climate change, characterized by global warming and precipitation extremes, as well as anthropogenic activities including rapid urban growth, are involved in the furious turbulence of hydroclimatic extremes (Clark et al., 2016; Nathan et al., 2019). Global warming caused by greenhouse gas emissions can change atmospheric humidity and disturb the condition of atmospheric circulation, posing a dramatic effect on the characteristics of precipitation and the redistribution equilibrium of water resources (Li et al., 2019; Nilawar and Waikar et al., 2019; Paparrizos at al., 2015; Zhang et al., 2016). Many studies have therefore explored the impacts of climate change on the occurrence of extreme events, and demonstrated that the climate was projected to be warmer and wetter with time and the magnitude of the changes in extreme hydrological events would experience vital changes (Niu et al., 2021; Zhu et al., 2021; Dong et al., 2020).

It is effective to utilize Global Circulation Model (GCM) projections to drive hydrological model, such as the SWAT, VIC, MIKESHE and so on, to explore how climate conditions work on the hydrological process (Pastén-Zapata et al., 2020; Li and Fang, 2021). GCMs that have good capability in explicitly simulating average characteristics of temperature, precipitation, and circulation factors on a global scale provide credible information regarding the past, now, and future (Zhang et al., 2016). Given that GCMs lack accuracy in spatial and temporal resolution, researchers use regionally more relevant scale climate models to downscale future climate scenarios (Chen et al., 2011; Fowler and Kilsby, 2007). Particularly, the Statistical Downscaling Method (SDSM) model possesses the competence to apply climate information with greater physical significance and more accurate simulation in GCMs output to the statistical model (Wilby et al., 2002; Shen at al., 2018; Wilby and Dawson, 2007). This could reduce the system error of GCMs and as a consequence own an easy operation with excellent simulation effect. In hydrological and climatological studies, future climate scenarios are a reasonable description of the 
time and space distribution of the future climate state, which is based on certain driving forces and scientific assumptions. Representative Concentration Pathways (RCPs), as the most widely used future climate scenario, are advantageous for understanding the risks connected with different emission scenarios (Bhatta et al., 2019).

Over the past decades, many studies, highlighting the projected changes to weather and climate extremes, have been conducted, and most of them mainly focused on individual extremes or variables (Tofiq and Guven, 2015; Meaurio et al., 2017; Bulti et al., 2020). Conventionally, each hydrological variable interacts intricately instead of existing independently. There are many limitations in practical applications when analyzing the frequency only considering the influence of a single factor which cannot accurately describe the relationship between the variables. To investigate the joint probabilistic behavior of extreme events, multivariate probabilistic framework comes into being. The copula function (Skarl, 1995), which without restriction on the specification of marginal distributions and their uniformity, is conducive to deduce the joint probability distribution of random variables (Favre et al., 2004;Joe, 2014). A number of univariate and copula-based multivariate approaches were developed for co-occurrence frequency analysis of extremes, such as drought (Ayantobo et al., 2018; Sun et al.,2019; Li et al.,2020; Xu et al., 2020), and flooding hazard (Muñoz et al., 2020; Balistrocchi et al., 2017; Yu et al., 2019; Yin et al., 2018; Liu et al., 2020; Vinnarasi and Dhanya, 2019), thereby providing a joint frequency perspective of the associative structure between the depicted factors. For instance, Sun et al(2019)utilized a multidimensional copula model to combine the two kinds of disaster in terms of investigating the potential two future scenarios impacts on the simultaneous occurrence and joint return period of droughts and hot extremes in the Loess Plateau of China, and found that the compounding occurrence of drought with long-term hot extremes will be more severe and frequent. Muñoz et al (2020) evaluated compounding effects of terrestrial and coastal flood drivers and wetland elevation accuracy on maximum floodwater height and velocity with a bivariate statistical analysis framework. Yin et al (2018) explored the variations of flood peak and volume in Ganjiang River basin under different climate scenarios by fitting univariate and copula-based bivariate distribution, which indicated that the impacts of climate change on the future bivariate flood quantiles are considerable.

Centered on the Yangtze River Delta region, the joint frequency analysis of the multivariate characteristics based on the coupled extreme precipitation-streamflow under changing climate is rarely inquired about in literature. Furthermore, flood is one of the most destructive and widespread natural disasters over China, and climate change has anticipated to exacerbate the frequency of extreme flood events in the future. Herein, this research aims to detect the joint responses of extreme precipitation and floods under the climate changing environment by establishing suitable marginal and two-dimensional Copula function of the extreme precipitation and streamflow, which expands on our previous work (Wang et al., 2020). The results would improve the acknowledge of the disaster-causing process in watershed flood; thereafter, actionable insights are provided for decision makers to formulate the planning scheme of flood control and disaster reduction.

Clearly, the overarching structure of the research is organized as follows. In section 2, the study area and data involved in this paper are displayed. Section 3 is devoted to the methodologies used in the paper, including the prediction technique of extreme events and the copula method. In Section 4, the best fitted marginal and joint distributions are established through Copula functions, in order to evaluate the impact of climate change on the frequency of univariate and bivariate joint design events. At last, conclusions are presented.

\section{Study Area And Datasets}

\subsection{Study Area}

The Xitiaoxi River Basin (XRB), located between $119^{\circ} 14^{\prime} \mathrm{E}-119^{\circ} 45^{\prime} \mathrm{E}$ and $30^{\circ} 23^{\prime} \mathrm{N}-31^{\circ} 11^{\prime} \mathrm{N}$ within the Yangtze River Delta, is one of the major tributaries of the upper reaches of Taihu Lake (Figure 1). The south and northwest part of XRB distributes mountains, and flat alluvial plain lies in the northeastern part (Zhang et al., 2011; Zhao et al., 2011). The basin dominates by subtropical monsoon climate with an average annual temperature of $15.5^{\circ} \mathrm{C}$ and a mean annual rainfall of $1584 \mathrm{~mm}$. Specially, the flood season (from April to October) contains over $70 \%$ of the rainfall. As one of the three largest water volume supplies (approximately 27.7\%) of Taihu Lake, the XRB is acknowledged to be an area experienced rapid development of 
urbanization and turbulent climate change that may affect the occurrence mechanism of local extreme hydrological events. Thus, based on the representative region of the Yangtze River Delta-the XRB, this research aimed to demonstrate the interresponse between extreme hydroclimatic events under future climate scenarios.

\subsection{Datasets}

The datasets used mainly includes the reanalysis data desired by the SDSM model, and the data required for driving the SWAT model. Detailed presentations of data usage are shown in Table 1. The National Centers for Environment Prediction (NCEP) reanalysis data, GCMs future scenario output factors and historical meteorological data were applied to conduct statistically downscaling. The NCEP reanalysis data comprised the daily series of 26 atmospheric circulation factors for the time period 1961 to 2015 with a $2.5^{\circ} \times 2.5^{\circ}$ horizontal resolution. Three GCMs, namely the BCC-CSM 1.1 (Beijing Climate Center, Climate System Model, version1.1), the NorESM1-M (Norwegian Earth System Model, version 1), and the CanESM2 (Second Generation Canadian Earth System Model), under RCP2.6, RCP4.5 and RCP8.5 emission scenarios, were utilized for exporting the historical and future climate time series data. All GCM datasets were uniformed to the same resolution of NCEP to avoid any biases caused by differences in scale. The observed weather data included daily precipitation(mm), minimum and maximum temperature $\left({ }^{\circ} \mathrm{C}\right)$ covering the period between 1961 and 2015 . Two representative periods of climate projection scenarios (2006-2099) are selected, i.e., the mid-century scenario (2036-2065, the 2050s) and the late-century scenario (2070-2099, 2080s), compared with the baseline period (1961-1990, 1970s) of the three GCMs. To minimize climate change projections uncertainty caused by the differences of parameterization schemes in various GCMs, the ensemble means of the output in the three GCMs were then implemented in this study.

Table 1

Data descriptions

\begin{tabular}{|c|c|c|c|}
\hline \multicolumn{2}{|l|}{ Data } & \multirow{2}{*}{$\begin{array}{l}\text { Description } \\
30 \mathrm{~m}\end{array}$} & \multirow{2}{*}{$\begin{array}{l}\text { Sources } \\
\text { the ASTER GDEM datasets } \\
\text { provided by the Computer } \\
\text { Network Information Center at the } \\
\text { Chinese Academy of Sciences } \\
\text { (http://www.gscloud.cn) }\end{array}$} \\
\hline $\begin{array}{l}\text { Geographic } \\
\text { Data }\end{array}$ & DEM & & \\
\hline & $\begin{array}{l}\text { soil } \\
\text { information }\end{array}$ & 1: 10000 & $\begin{array}{l}\text { the Second National General Soil } \\
\text { Survey data; Anji Bureau of } \\
\text { Agriculture }\end{array}$ \\
\hline & $\begin{array}{l}\text { land use } \\
\text { data }\end{array}$ & $30 \mathrm{~m}$ & $\begin{array}{l}\text { digitizing land survey data on a } \\
\text { scale of } 1: 10,000\end{array}$ \\
\hline \multicolumn{2}{|c|}{ Hydrological Data } & $\begin{array}{l}\text { daily streamflow from } 1994 \text { to } 2015 \text { in three } \\
\text { hydrological stations; daily precipitation of } 16 \text { rainfall } \\
\text { station from } 1972 \text { to } 2015\end{array}$ & $\begin{array}{l}\text { Anji Hydrology and Water } \\
\text { Resources Investigation Bureau }\end{array}$ \\
\hline \multicolumn{2}{|c|}{ Reanalysis datasets } & $\begin{array}{l}\text { large-scale atmospheric observation variables with a } \\
\text { resolution of } 2.5^{\circ} \text { (longitude) } \times 2.5^{\circ} \text { (latitude) from } \\
1961 \text { to } 2015 ; \text { daily interval for each of the RCPs' } \\
\text { historical periods }(1961-2000) \text { and future scenarios } \\
(2006-2099)\end{array}$ & $\begin{array}{l}\text { the National Centers for } \\
\text { Environment Prediction (NCEP); } \\
\text { the website of the Earth System } \\
\text { Grid Federation (https://esgf- } \\
\text { node.IInl.gov/). }\end{array}$ \\
\hline
\end{tabular}

Geographic data and observation data are required to set up the hydrological SWAT model. A GIS database including the digital elevation model (DEM), land use and land cover, and soil map datasets. Five climate variables, namely, daily maximum and minimum temperature, mean wind speed, relative humidity, and solar radiation measurements were provided as input with daily interval for the period from 1961 to 2015. Daily streamflow data during 1994-2015 was obtained from the Laoshikan Reservoir, Fushi Reservoir, and Hengtangcun Station. Hydrometeorological data taken from 1994 to 2015 were used for the construction, calibration and validation of the hydrological model.

\section{Methods}


For this study, a hybrid method, coupling hydroclimatic models with copula functions, was applied to investigate the univariate and multivariate variation characteristics of hydrological extreme event under future scenarios. Using a statistical downscaling model (SDSM), daily precipitation and other climate variables for the historical and future periods were projected from the outputs of three GCMs under three climate change scenarios. The hydrological processes of XRB were simulated by SWAT model to export streamflow during 1961-2099. Copula models were utilized to investigate the impacts of climate change on the univariate and multivariate extreme precipitation and flood events. A schematic flowchart of the methodology applied in this research is given in Fig. 2 .

\subsection{Hydrological model and Extreme indices}

The Soil and Water Assessment Tool, developed by United States Department of Agriculture's Agriculture Research Service (Arnold et al., 1999), can effectively simulate hydrological processes such as runoff and evapotranspiration for a watershed. SWAT is popular in assessing runoff responses in watersheds around the world for its strong portability, suitability for scenario analysis, and friendly interface.

The SDSM (Wilby, et al., 2002) is a combination of conditional weather generator and multiple regression analysis that can be used to evaluate and predict time-varying meteorological parameters describing local variables. Hence, SDSM establishes mathematical relationship and downscaling the climatic data between regional predictors from GCMs and local predictands by regression and stochastic approaches.

Our previous study (Wang et al., 2020) showed that the SWAT and SDSM model exhibits sufficiently capable of simulating the hydrological processes and estimating regional climate scenarios for the XRB. Through the integrated application of SWAT and SDSM model, extreme precipitation and streamflow data under future scenarios are simulated and predicted to detect the variation characteristics of the joint frequency. In this study, two extreme flood event indicators are selected: (1) a precipitation index (Annual maximum 1-day precipitation, Rx1day, mm); (2) a river discharge index (Annual highest daily flow, $\mathrm{Sx} 1 \mathrm{day}, \mathrm{m}^{3} / \mathrm{s}$ ). They are extracted from data series of precipitation and streamflow in different periods under diverse climate scenarios in XRB by Annual maximum sampling method.

\subsection{Copulas theory}

It is important to note that hydrological variables are interrelated, hence, univariate analysis is not competent to provide integrated research of flood (Liu et al., 2020). The Copula function, initially raised by Sklarin 1950s, is an expression that can construct the multidimensional joint distribution of two or more independent variables by marginal distributions and correlation framework (Sklar, 1959; Nelsen, 2007; Li et al., 2018; Salvadori and De Michele, 2007). The copulas have been broadly used to explore the correlation structure between variables regardless of their marginal distribution types in hydrological extremes study. According to the Sklar's theorem, the two-dimensional copula function can be expressed as follows:

$$
F(a, b)=C_{\theta}\left(F_{1}(a), F_{2}(b)\right)=C_{\theta}\left(u_{1}, u_{2}\right), \quad a, b \in R
$$

in which $F(a, b)$ is joint distribution. The function $C$ is a two-dimensional copula in the form $[0,1] \times[0,1] \rightarrow[0,1]$ of the pair $(a, b)$. Where $F_{1}(a)$ and $F_{2}(b)$, denoted by $u_{1}$ and $u_{2}$ respectively, represent marginal cumulative distribution functions of random variables $a$ and $b$. And $\theta$ indicates parameter of the time-dependent copula. Most researchers concentrate on a handful of copulas (i.e., Frank, Clayton, Gaussian and Joe) resulting a negligence of exploring more suitable copulas. Copula families

differ in describing dependence structure and the parameter uncertainty of variables in details. More copulas that have not been completely explored in the hydrological and climatological literature should be considered (i.e., Tawn and Burr).

\subsubsection{Establishment of Marginal Distribution Function}


Parameters of seventeen probability distribution functions are calculated by a maximum likelihood algorithm that minimizes the distance between observations and model simulations. Then the BIC (Bayesian Information Criterion) metric is used to select the most suitable marginal distribution. What's more, the chis-squared ( $\chi 2)$ goodness-of-fit test is applied to statistically describe whether or not a probability distribution fits the observed data. The Quantile-Quantile (Q-Q) plotting aims to compare the fitting effect of the function and empirical probability values.

To determine whether there was an inter-dependency between the extreme precipitation and extreme streamflow for different correlation coefficients namely, Kendall rank, Spearman's rank-order, and Pearson product-moment correlation coefficients, are used in this paper to assess the correlation relationship between the two variables.

\subsubsection{Selection of fit Copula function}

Quantitatively identifying the reliability of copula function is required to effectively construct the structure of dependence between extreme precipitation and streamflow. The optimal copula which we have used in this investigation were identified using five model performance indices, the root mean square error (RMSE) (Willmott et al., 1985), the Nash-Sutcliffe efficiency (NSE) (Zhang and Singh, 2007), Akaike's information criterion (AIC) (Akaike, 1987), the maximum likelihood estimation (MLE) (Sorooshian and Dracap, 1980) and BIC (Schwarz, 1978). Their equations are formulated as follows:

$$
\begin{aligned}
R M S E & =\sqrt{\frac{1}{N} \sum_{i=1}^{N}\left[x_{e}(i)-x_{o}(i)\right]^{2}} \\
N S E & =1-\frac{\sum_{i=1}^{N}\left[x_{e}(i)-x_{o}(i)\right]^{2}}{\sum_{i=1}^{N}\left[x_{e}(i)-\bar{x}_{e}(i)\right]^{2}} \\
A I C & =N \cdot \ln \left((R M S E)^{2}\right)+2 k \\
\mathrm{MLE} & =\prod_{i=1}^{N} \frac{\exp \left\{-\frac{\left[x_{e}(i)-x_{o}(i)\right]^{2}}{2(R M S E)^{2}}\right\}}{\sqrt{2 \pi(R M S E)^{2}}} \\
\mathrm{BIC} & =k \ln N+N \cdot \ln \left((R M S E)^{2}\right)
\end{aligned}
$$

Where $N$ is the number of observations; $i$ is the serial number of the observation; $x_{e}(i)$ represents the multivariate empirical probability of observations and $x_{o}(i)$ represents the theoretical probability using fitted probability distribution; $k$ is the unknown number of parameters of probability functions. The RMSE varies in the interval 0 to $+\infty$, and a lower RMSE value associates with a more perfect model fit. In general, a copula model is reliable for hydrological extreme event when the NSE is larger than 0.75 , in which the range of changes is from -1 to 1 (Motovilov et al., 1999). Compared with MLE, where a larger value is preferred, the lower the coefficients of AIC and BIC (negative), the better the copula model.

\subsubsection{Univariate and bivariate return period}

Once the marginal distributions of Rx1day and Sx1day are defined, the univariate return periods of extreme risk are also derived under the historical and future scenarios. The relevant calculation formulas can be expressed as follows:

$$
T=\frac{1}{1-F(x)}
$$

Where $T$ denotes the return periods for a Rx1day or Sx1day greater than or equal to certain values of $x$. $F$ means the cumulative probability distribution functions of Rx1day or Sx1day. To obtain the joint probabilistic characteristics between the two dependent variables, the copula function of joint return periods is determined:

$$
T_{\text {joint }}=\frac{1}{1-C\left(F_{R}(r), F_{D}(d)\right)}
$$


Where $T_{\text {joint }}$ represent the joint return period when $R \geq r$ or $D \geq d$.

The bivariate statistical analysis under uncertain is assessed based on the Multivariate Copula Analysis Toolbox (MvCAT) developed by Sadegh et al. $(2017,2018)$, which can calculate the marginal distribution for each extreme indicator and select the most suitable copula function for pair-wise variables. Firstly, to find an appropriate model that optimally fits the available data, the parameters of the 17 different marginal probability distribution functions were estimated in MvCAT. And then, a total of 26 copula distribution families for bivariate modeling were selected to develop the one that best describes the joint dependence structure of extreme precipitation and extreme streamflow based on the univariate marginal function. The mathematical expression of these copulas is available in Table 1 of Sadegh et al. (2017).

\section{Results And Discussion}

\subsection{Marginal and joint probability distribution of Rx1day and Sx1day}

The Kendall, Spearman and Pearson correlation coefficients were figured to evaluate the dependence between(Rx1day, Sx1day)pairs under historical and future climate scenarios, and their caculated values are listed in Table 2. The coefficients exhibit a statistically significant relation at the 0.05 significance level, indicating that the factors under each scenario present strong positive correlation. Hence, the two variables can be used to construct the joint distribution function through the Copula function.

Table 2

Fitted Marginal Distributions and Correlation Structure between Rx1day and Sx1day

\begin{tabular}{|c|c|c|c|c|c|c|}
\hline \multirow{2}{*}{$\begin{array}{l}\text { Climate } \\
\text { scenarios }\end{array}$} & \multicolumn{3}{|c|}{ Correlation Coefficient } & \multirow{2}{*}{$\begin{array}{l}\text { Significant at } \\
5 \%\end{array}$} & \multicolumn{2}{|c|}{ Marginal Distribution } \\
\hline & $\begin{array}{l}\text { Kendall } \\
\text { rank }\end{array}$ & Spearman & Pearson & & Rx1day & Sx1day \\
\hline $1970 s$ & 0.4189 & 0.5585 & 0.6796 & Yes & loglogistic & gamma \\
\hline RCP2.6 2050s & 0.4069 & 0.5582 & 0.5501 & Yes & weibull & inverse gaussian \\
\hline RCP2.6 2080s & 0.4437 & 0.6156 & 0.6166 & Yes & loglogistic & gamma \\
\hline RCP4.5 2050s & 0.5908 & 0.8158 & 0.8172 & Yes & inverse gaussian & inverse gaussian \\
\hline RCP4.5 2080s & 0.5816 & 0.7829 & 0.7371 & Yes & generalized pareto & inverse gaussian \\
\hline RCP8.5 2050s & 0.4759 & 0.6565 & 0.7242 & Yes & generalized pareto & loglogistic \\
\hline RCP8.5 2080s & 0.3230 & 0.4325 & 0.6586 & Yes & loglogistic & loglogistic \\
\hline
\end{tabular}

Seventeen univariate distributions, out of which the most suitable one is chosen based on the BIC metric, were selected as candidates to fit the simulative and predicted data in terms of Rx1day and Sx1day from the XRB. The parameters and goodness-of-fit of each marginal distribution was estimated using Chi-square tests. All of the fitted univariate distributions passed the Chi-square test, that is, at $5 \%$ level. A summary of best marginal distributions fitted to Rx 1 day and Sx 1 day is presented in Table 2.

According to the optimal marginal distribution function mentioned in the above analysis, empirical and theoretical data for each variable is established. Fig. 3 and Fig. 4 illustrate the corresponding relations between the fitted and empirical probability of Rx1day and Sx1day. Q-Q plots visually present goodness-of-fit of fitted data to empirical data, showing that they are suitable for building joint dependence. The joint probability distributions between Rx1day and Sx1day under different scenarios were examined using RMSE, NSE, MLE, AIC and BIC. The evaluation metrics suggest that these corresponding best models exhibit an acceptable level of fit, indicating that the selected Copula Functions should be used in this investigation (Table 3). 
Table 3

Evaluation value of Copula function for fitting the joint distribution of Rx1day and Sx1day

\begin{tabular}{|lllllll|}
\hline Climate scenarios & Best copulas & RMSE & NSE & MLE & AIC & BIC \\
\hline 1970s & Tawn & 0.1465 & 0.9919 & 108.6407 & -211.2814 & -207.0778 \\
\hline RCP2.6 2050s & Burr & 0.1703 & 0.9865 & 104.1318 & -206.2637 & -204.8625 \\
\hline RCP2.6 2080s & Tawn & 0.1581 & 0.9898 & 106.3596 & -206.7192 & -202.5156 \\
\hline RCP4.5 2050s & Clayton & 0.2436 & 0.9709 & 93.3875 & -184.7750 & -183.3738 \\
\hline RCP4.5 2080s & Joe & 0.2586 & 0.9705 & 91.5914 & -181.1829 & -179.7817 \\
\hline RCP8.5 2050s & Burr & 0.1595 & 0.9878 & 106.0883 & -210.1766 & -208.7754 \\
\hline RCP8.5 2080s & Joe & 0.2550 & 0.9715 & 92.0136 & -182.0271 & -180.6259 \\
\hline
\end{tabular}

\subsection{Impacts of climate change on individual extreme hydrological events using univariate frequency analysis}

Figure 5 demonstrates the marginal return period for Rx1day and Sx1day for the history and future periods under RCP 2.6, RCP 4.5 and RCP 8.5, respectively, with the corresponding quantiles of Rx1day and Sx1day for different return periods ( $T=2 a$, 5a, 10a, 25a, 50a, 100a) as illustrated in Table 4. The results showed that the corresponding values of Rx1day and Sx1day for a certain return period in future climate conditions (i.e., 2050s and 2080s) are higher than those in historic period, i.e., 1970s, especially under the RCP 8.5 scenarios. In addition, climate change under the low emission scenario (RCP 2.6) have relative greater impacts on precipitation events with lower return periods, such as $2 \mathrm{a}, 5 \mathrm{a}$, and $10 \mathrm{a}$, during the periods of 2050s, while the impacts of climatic changes under higher emission scenarios (RCP 4.5 and RCP 8.5) on rainfall events with higher return periods, such as $25 \mathrm{a}, 50 \mathrm{a}$, and $100 \mathrm{a}$, are greater at the same return periods (Fig. $5 \mathrm{a}$ and Table 4). With the respects of the periods of 2080s, climate change has relative greater impacts on rainfall events with high return periods, such as 25a, 50a, and 100a, except for RCP4.5 scenarios (Fig. 5b and Table 4). Similarly, climatic change impacts on Sx1day with high return periods are greater for the periods of both 2050 s and 2080 s under the three emission scenarios (Fig. 5c-4d and Table 4). 
Table 4

Comparison of univariate changes between historical and future periods under univariate analysis

\begin{tabular}{|c|c|c|c|c|c|c|c|c|}
\hline \multirow{2}{*}{$\begin{array}{l}\text { Extreme } \\
\text { indices }\end{array}$} & \multirow{2}{*}{$\begin{array}{l}\text { Return } \\
\text { period }\end{array}$} & \multicolumn{7}{|c|}{ Climate scenarios } \\
\hline & & 1970s & $\begin{array}{l}\text { RCP2.6 } \\
\text { 2050s }\end{array}$ & $\begin{array}{l}\text { RCP } 4.5 \\
2050 s\end{array}$ & $\begin{array}{l}\text { RCP8.5 } \\
\text { 2050s }\end{array}$ & $\begin{array}{l}\text { RCP2.6 } \\
\text { 2080s }\end{array}$ & $\begin{array}{l}\text { RCP4.5 } \\
2080 s\end{array}$ & $\begin{array}{l}\text { RCP8.5 } \\
2080 s\end{array}$ \\
\hline \multirow{6}{*}{$\begin{array}{l}\text { Rx1day } \\
(\mathrm{mm})\end{array}$} & $2 a$ & 27.2 & $28.8(5.9)$ & $27.8(2.2)$ & $27.1(-0.4)$ & 27.5(1.1) & $28.3(4.0)$ & $29.3(7.7)$ \\
\hline & $5 a$ & 28.7 & $30.9(7.7)$ & $30.0(4.5)$ & $29.7(3.5)$ & $29.4(2.4)$ & $31.3(9.1)$ & $31.3(9.1)$ \\
\hline & $10 a$ & 29.6 & $31.8(7.4)$ & $31.3(5.7)$ & $31.3(5.7)$ & $30.5(3.0)$ & $32.3(9.1)$ & $32.5(9.8)$ \\
\hline & $25 a$ & 30.8 & $32.78(6.4)$ & $32.78(6.4)$ & $33.1(7.5)$ & $32.0(3.9)$ & $32.8(6.5)$ & $34.0(10.4)$ \\
\hline & $50 a$ & 31.7 & $33.3(5.0)$ & $33.7(6.3)$ & $34.2(7.9)$ & $33.1(4.4)$ & $33.0(4.1)$ & $35.1(10.7)$ \\
\hline & $100 a$ & 32.5 & $33.7(3.7)$ & $34.6(6.5)$ & $35.1(8.0)$ & $34.2(5.2)$ & $33.1(1.8)$ & $36.3(11.7)$ \\
\hline \multirow{6}{*}{$\begin{array}{l}\text { Sx1day } \\
\left(m^{3} / s\right)\end{array}$} & $2 a$ & 150.01 & $158.18(5.4)$ & $152.09(1.4)$ & 155.85(3.9) & $158.43(5.6)$ & 151.09(0.7) & $180.65(20.4)$ \\
\hline & $5 a$ & 168.36 & $177.81(5.6)$ & $174.73(3.8)$ & 173.82(3.2) & $180.20(7.0)$ & $177.04(5.2)$ & 197.41(17.3) \\
\hline & $10 a$ & 178.51 & $189.00(5.9)$ & $187.85(5.2)$ & $185.28(3.8)$ & 191.95(7.5) & 191.79(7.4) & 207.58(16.3) \\
\hline & $25 a$ & 189.78 & $201.68(6.3)$ & 202.87(6.9) & $200.16(5.5)$ & $205.84(8.5)$ & 209.90(10.6) & 221.42(16.7) \\
\hline & $50 a$ & 197.26 & $210.26(6.6)$ & 213.12(8.0) & 211.69(7.3) & $214.85(8.9)$ & $222.01(12.5)$ & 231.73(17.5) \\
\hline & $100 a$ & 204.19 & $218.29(6.9)$ & 222.78(9.1) & 223.73(9.6) & 223.20(9.3) & $233.49(14.3)$ & $242.39(18.7)$ \\
\hline
\end{tabular}

Note. Values shown in parenthesis () are variations (\%) of future scenarios compared to historical period.

It can be seen that the changes of Rx1day and Sx1day in future period, compared to those values in historical scenarios, increase with the return period, and Sx1day show a larger increment than Rx1day. The Rx1day and Sx1day under future scenarios increased by $-0.4 \sim 11.7 \%$ and $0.7 \sim 20.4 \%$, respectively, compared to historical periods. Above results imply that the changing environment has severer impacts on Sx1day than Rx1day, especially under the RCP 8.5 scenarios. This is consistent with the findings in the literatures that the future projected streamflow appears to increase in general and shows fairly dramatic growths under RCP8.5 scenario (Nilawar and Waikar, 2019; Zhang et al., 2016). These findings suggest that the XRB may suffer higher flood risk in the future. Since precipitation is recognized to be the direct influence factor of the flood, these changes in streamflow were closely related to simultaneous changes in precipitation (Li and Fang, 2021). Variation of floods will also magnify the impact of climate change on precipitation in reverse, therefore, further analysis is needed through joint frequency.

\subsection{Impacts of climate change on compound extreme precipitation- flood events using bivariate frequency analysis}

The curves for joint return period of Rx1day and Sx1day under historical and future scenarios are demonstrated in Figure 6. The colored lines represent the combined probability of extreme precipitation and extreme flood events, and the possibility of simultaneous occurrence of the two events is reflected in the value of probability densities. For the sake of explanation, the interval where the combined probability of Rx 1 day and Sx 1 day is greater than $50 \%$ is expressed as the combination interval with high probability.

For the historical and RCP 2.6 scenarios, the intervals of Rx1day are narrow and which of Sx1day are wider under each return period, that is, Sx1day is greatly affected by Rx1day in these situations (Fig. 6a-6c). In the time periods of 2050s under the RCP 4.5 scenario, it is evident that the corresponding relationship between the Rx1day and Sx1day with joint return periods higher than $5 \mathrm{a}$ is not obvious (Fig. 6d). As to the periods of 2080 s, the combination interval with a high probability of Rx1day and Sx1day is relatively concentrated, which indicates that the variation range of Rx1day, as well as Sx 1 day, is slight at this 
stage (Fig. 6e). Figure $6 \mathrm{f}$ reflects that the higher the return periods are, the larger the values of Rx1day are in high probability combination interval in the 2050s under the RCP 8.5 scenario. Whereas the variation range of Sx1day does not change much with the regular change of return period, which revealed that the influence of Rx1day on Sx1day gradually weakens with the increase of the joint return period. During the 2080s, the fitted results represent that Rx1day and Sx1day have a good correlation because of the little variation ranges of Rx1day and Sx1day with return period.

Table 5 shows the variation range of Rx1day and Sx1day in high probability combination interval. Here we mainly focus on events under historical, RCP 2.6 and RCP 8.5 scenarios, since the changing trend of the two variables is not obvious under the RCP 4.5 scenario. From the perspective of different return periods, the joint return periods for compound events higher than $5 \mathrm{a}$ in the listed combination interval under the two future scenarios are visibly greater than the those in historical scenario, particularly for the RCP 8.5 scenario. And the relevant Rx1day and Sx1day values cover a broader range, for example, under RCP 8.5 scenario, the 50a combination interval covering a range with marginal Rx1day values in the 1970s, 2050s, and 2080s ranging from $31.7 \mathrm{~mm}$ to $31.9 \mathrm{~mm}, 34.2 \mathrm{~mm}$ to $35.1 \mathrm{~mm}$, and $35.2 \mathrm{~mm}$ to $36.6 \mathrm{~mm}$, respectively. This suggests that smaller combinations of Rx1day and Sx1day that can induce a 50a event in the 1970s are less likely to prompt such dangerous events in future scenarios and the flood risk is comparatively higher in the future. It can be qualitatively judged that emission scenarios have a driving effect on the rising coactivity of bivariate combination of Rx 1 day and Sx 1 day.

Table 5

Combination interval with high probability of Rx1day and Sx1day in each joint return period

\begin{tabular}{|c|c|c|c|c|c|c|}
\hline $\begin{array}{l}\text { Extreme } \\
\text { indices }\end{array}$ & $\begin{array}{l}\text { Return } \\
\text { period }\end{array}$ & 1970 s & RCP2.6 2050s & RCP8.5 2050s & RCP2.6 2080s & RCP8.5 2080s \\
\hline \multirow{6}{*}{$\begin{array}{l}\text { Rx1day } \\
\text { (mm) }\end{array}$} & $2 a$ & $27.2 \sim 27.5$ & $28.9 \sim 30.8$ & $27.2 \sim 29$ & $27.6 \sim 28.4$ & $29.4 \sim 31.1$ \\
\hline & $5 a$ & $28.7 \sim 29$ & $31 \sim 32.1$ & $29.8 \sim 31.2$ & $29.4 \sim 30.0$ & $31.3 \sim 32.7$ \\
\hline & $10 a$ & 29.7 29.8 & $31.9 \sim 32.8$ & $31.4 \sim 32.6$ & $30.6 \sim 31.1$ & $32.5 \sim 33.8$ \\
\hline & $25 a$ & $30.8 \sim 31$ & $32.7 \sim 33.4$ & $33.1 \sim 34.1$ & $32.0 \sim 32.6$ & $34.0 \sim 35.4$ \\
\hline & $50 a$ & $31.7 \sim 31.9$ & $33.3 \sim 33.9$ & $34.2 \sim 35.1$ & $33.1 \sim 33.7$ & $35.2 \sim 36.6$ \\
\hline & $100 a$ & $32.6 \sim 32.7$ & 33.7 34.2 & $35.1 \sim 35.8$ & $34.2 \sim 34.8$ & $36.4 \sim 37.8$ \\
\hline \multirow{6}{*}{$\begin{array}{l}\text { Sx1day } \\
\left(\mathrm{m}^{3} / \mathrm{s}\right)\end{array}$} & $2 a$ & 160.09 167.05 & 158.97 176.98 & 156.55 168.45 & 164.79 178.85 & 181.42 195.79 \\
\hline & $5 a$ & 176.98 181.66 & 178.45 190.87 & $174.23 \sim 184.53$ & 185.79 196.57 & 197.99 209.41 \\
\hline & $10 a$ & $186.11 \sim 189.25$ & 189.36 202.11 & 185.67 195.75 & 197.54 206.83 & 208.65 218.27 \\
\hline & $25 a$ & 196.51 200.82 & 202.11 213.12 & $200.67 \sim 211.02$ & $210.42 \sim 220.11$ & 221.98 233.67 \\
\hline & $50 a$ & 203.53 207.56 & $210.68 \sim 220.78$ & 212.21 222.37 & 219.14 227.95 & $232.35 \sim 244.40$ \\
\hline & $100 a$ & 210.12 213.11 & 218.63 228.25 & 224.27 235.27 & 227.29 235.83 & 243.03 255.18 \\
\hline
\end{tabular}

In the 2050s, the climate change during RCP 8.5 scenario in larger return periods have a more significant influence on the rise of combination values than in small return periods, compared to the RCP 2.6 scenario. The design values of Sx 1 day in combination interval for 2a joint return period under the RCP 2.6 and RCP 8.5 scenarios range from $158.97 \mathrm{~m}^{3} / \mathrm{s}$ to 176.98 $\mathrm{m}^{3} / \mathrm{s}$ and from $156.55 \mathrm{~m}^{3} / \mathrm{s}$ to $168.45 \mathrm{~m}^{3} / \mathrm{s}$, respectively. While for 100 a joint return period, the values range from 218.63 $\mathrm{m}^{3} / \mathrm{s}$ to $228.25 \mathrm{~m}^{3} / \mathrm{s}$ under the 2.6 scenario and from $224.27 \mathrm{~m}^{3} / \mathrm{s}$ to $235.27 \mathrm{~m}^{3} / \mathrm{s}$ under the 8.5 scenario. However, the climate under the RCP 8.5 scenario always keeps a stronger driving effect on the increase of Rx1day and Sx1day under each joint return period, and the corresponding values of Rx1day and Sx1day in combination interval are also covering a wider range in the 2080s. This indicates that future extreme flood events are more uncertain and more difficult to predict. Variation making in persistence, predictability, and probability of atmospheric patterns and the selection of copula function would exert an influence on the uncertainty range of extreme events (Faranda et al., 2020 ; Stottl, 2016; Liu et al., 2020). Overall, the 
driving effect of high emission scenario on extreme precipitation and floods is more obvious for events with higher return period, especially in the period of 2080 s.

\subsection{Comparison of univariate and bivariate joint analysis}

The extreme precipitation and flood under certain return periods generated by bivariate joint analysis during historical and future periods are showed in Figure 7. Both the Rx1day and Sx1day show an upward trend, and the design values of bivariate joint analysis are larger than that of univariate analysis for most return periods. It can be noticed from Fig. 7 that the change degree of Rx1day and Sx1day during the historical period and future scenarios show little difference for larger return periods. For example, the design values of Rx1day under 2a return period increases from $28.8 \mathrm{~mm}$ in univariate analysis to $28.5 \mathrm{~mm}$ in bivariate joint analysis by $2.4 \%$ for the RCP2.6 in the 2050s (figure $7 \mathrm{~b}$ ). While the values under 100a return period are 33.7 $\mathrm{mm}$ in univariate analysis and $33.9 \mathrm{~mm}$ in bivariate joint analysis (increased by $0.6 \%$ ). The changes of other design values of Rx1day and Sx1day under two climate scenarios during 2050s and 2080s are similar. These results imply that the joint combination contribute to a safer design criteria, and the flood frequency design deduced by bivariate joint distribution is securer than that by univariate distribution. Considering the security of water engineering, flood control design based on the joint distribution of two variables can reduce the risk of flood disaster (Lin et al., 2021).

\section{Summary And Conclusions}

Flood is a main natural disaster occurring on the Yangtze River Delta, and climate change has anticipated to exacerbate extreme flood events. Thus it is important to take the change into account when exploring the hydrological response for future flood characteristics. To identify the univariate and bivariate joint frequency of hydrological extreme events at different climate scenarios during historical and future period, we applied an integrated framework with the combination of the climatic simulation under three GCMs, streamflow simulation and projection based on the SWAT model, and univariate and bivariate frequency analysis according to marginal distribution functions and copula-based models. Compared with the historical period, the impacts of climate changes on extreme precipitation and streamflow in the XRB were quantified. The main conclusions are summarized as follows:

1) Based on univariate frequency analysis, the corresponding threshold of Rx1day and Sx1day in future period are larger than those in the historical period under the same return period. Compared to historical period, the Rx1day and Sx1day under future scenarios increased by $-0.4 \% \sim 11.7 \%$ and $0.7 \% \sim 20.4 \%$, respectively, indicating that the magnitude of flood would be higher under future climate conditions.

2) In case of bivariate joint analysis, there is a considerable increase of Sx1day with the increase of Rx1day, and flood is greatly affected by precipitation in these situations during the 1970s under RCP 2.6 scenario. However, the effect of extreme precipitation to flood gradually weakens with the increase of joint return period in the 2050s under the RCP 8.5 scenario.

3) Rx1day and Sx1day with high probability combination interval in the future are dramatically larger than those of historical scenario, together with a broader variations range, especially during 2080s under RCP 8.5 scenario. This demonstrates that future extreme flood events are more uncertain and more difficult to predict. The effects of climate change on the enhancement of Rx1day and Sx1day are more obvious for higher return period events, especially during 2080s.

4) By the comparation of univariate and bivariate frequency analysis, the results reveal that the flood frequency design deduced by bivariate joint distribution is more safer than that by univariate distribution. Affected by the changing environment, the rainstorm and flood disasters in XRB are likely to occur more frequently, which indicating the urgent needs for the safer flood frequency design.

In general, the intensity and frequency of extreme hydrological events are increasing under the changeful climatic environment, and this study also indicates that the different enhancements extreme events under different emission scenario of carbon dioxide, which should cause the attention of relevant departments. It should be noticed that this study only focuses

Page $11 / 21$ 
on the impact of different climate scenarios on regional hydrological processes. However, the influence of climate change on floods is a comprehensive result; the responsiveness of the different driving factors as well as the influence degree on the frequency of changes in regional hydrological processes, should be quantitatively analyzed in further research.

\section{Declarations}

Acknowledgments

This work was supported by the National Natural Science Foundation of China (No.42101020), China Postdoctoral Science Foundation (No. 2021M691529) and Jiangsu Postdoctoral Research Funding Program (No.2021K121B), and Water Conservancy Science and Technology Foundation of Jiangsu Province (No. 2021010).

Ethical Responsibilities of Authors

The authors declare that they have no known competing financial interests or personal relationships that could have appeared to influence the work reported in this paper. All procedures performed in studies involving human participants were in accordance with the ethical standards of the institutional and/or national research committee. All of the co-authors have reviewed the contents of this manuscript and have agreed to the submission.

\section{References}

1. Akaike H (1987) Factor analysis and AIC. Psychometrika 52:317-332. https://doi.org/10.1007/BF02294359

2. Arnold JG, Srinivasan R, Muttiah RS, Williams JR (1998) Large area hydrologic modeling and assessment part I: model development 1. JAWRA Journal of the American Water Resources Association 34(1):73-89. https://doi.org/10.1111/j.1752-1688.1998.tb05961.x

3. Ayantobo OO, Li Y, Song S (2019) Copula-based trivariate drought frequency analysis approach in seven climatic subregions of mainland China over 1961-2013. Theor Appl Climatol 137:2217-2237. https://doi.org/10.1007/s00704-0182724-x

4. Balistrocchi M, Orlandini S, Ranzi R, Bacchi B (2017) Copula-based modeling of flood control reservoirs. Water Resour Res 53:9883-9900. https://doi.org/10.1002/2017WR021345

5. Bhatta B, Shrestha S, Shrestha PK, Talchabhadel R (2019) Evaluation and application of a SWAT model to assess the climate change impact on the hydrology of the Himalayan River Basin. Catena 181:104082. https://doi.org/10.1016/j.catena.2019.104082

6. Blöschl G, Bierkens MFP, Chambel A, Cudennec C, Destouni G, Fiori A, Kirchner JW, McDonnell JJ, Savenije HHG, Sivapalan M (2019) Twenty-three unsolved problems in hydrology (UPH) - a community perspective. Hydrological Sciences Journal 64(10):1141-1158. https://doi.org/10.1080/02626667.2019.1620507

7. Bulti DT, Abebe BG, Biru Z (2020) Analysis of the changes in historical and future extreme precipitation under climate change in Adama city, Ethiopia. Modeling Earth Systems and Environment 1-13. https://doi.org/10.1007/s40808-02001019-x

8. Chen J, Brissette FP, Leconte R (2011) Uncertainty of downscaling method in quantifying the impact of climate change on hydrology. J Hydrol 401(3-4):190-202. https://doi.org/10.1016/j.jhydrol.2011.02.020

9. Chen Y, Moufouma-Okia W, Masson-Delmotte V, Zhai P, Pirani A (2018) Recent Progress and Emerging Topics onWeather and Climate Extremes Since the Fifth Assessment Report of the Intergovernmental Panel on Climate Change. Annu Rev Environ Resour 43:35-59. https://doi.org/10.1146/annurev-environ-102017-030052

10. Clark MP, Wilby RL, Gutmann ED, Vano JA, Gangopadhyay S, Wood AW, Fowler HJ, Prudhomme C, Arnold JR, Brekke LD (2016) Characterizing uncertainty of the hydrologic impacts of climate change. Current Climate Change Reports 2(2):55-64. https://doi.org/10.1007/s40641-016-0034-x

Page $12 / 21$ 
11. Dong G, Jiang Z, Tian Z, Buonomo E, Sun L, Fan D (2020) Projecting changes in mean and extreme precipitation over eastern China during 2041-2060. Earth and Space Science 7(9). https://doi.org/10.1029/2019EA001024. e2019EA001024

12. Faranda D, Vrac M, Yiou P, Jézéquel A, Thao S (2020) Changes in future synoptic circulation patterns: Consequences for extreme event attribution. Geophysical Research Letters. 47(15), e2020GL088002.

https://doi.org/10.1029/2020GL088002

13. Favre A-C, El Adlouni S, Perreault L, Thiemonge N, Bobee B (2004) Multivariate hydrological frequencyanalysis using copulas. Water Resour Res 40(1):W01101. https://doi.org/10.1029/2003WR002456

14. Fowler HJ, Kilsby CG (2007) Using regional climate model data to simulate historical and future river flows in Northwest England. Clim Change 80(3-4):337-367. https://doi.org/10.1007/s10584-006-9117-3

15. Garrote L, Granados A, Iglesias A (2016) Strategies to reduce water stress in Euro-Mediterranean river basins. Sci Total Environ 543:997-1009. https://doi.org/10.1016/j.scitotenv.2015.04.106

16. Han L, Xu Y, Yang L, Deng X (2015) Changing structure of precipitation evolution during 1957-2013 in Yangtze River Delta, China. Stoch Env Res Risk Assess 29(8):2201-2212. https://doi.org/10.1007/s00477-015-1034-4

17. Hao Z, Singh VP (2020) Compound events under global warming: a dependence perspective. J Hydrol Eng 25(9):03120001. https://doi.org/10.1061/(ASCE)HE.1943-5584.0001991

18. IPCC (2014) Climate change 2014: Impacts Adaptation and Vulnerability and Climate Change 2014: Mitigation of Climate Change. Contribution of working group II and working group III to the fifth assessment report of the IPCC. Cambridge University Press, New York

19. Jiang $X$, Luo Y, Zhang DL, Wu M (2020) Urbanization enhanced summertime extreme hourly precipitation over the Yangtze River Delta. J Clim 33(13):5809-5826. https://doi.org/10.1175/JCLI-D-19-0884.1

20. Joe $\mathrm{H}$ (2014) Dependence modeling with copulas. CRC press

21. Li C, Fang H (2021) Assessment of climate change impacts on the streamflow for the Mun River in the Mekong Basin, Southeast Asia: Using SWAT model. CATENA 201:105199. https://doi.org/10.1016/j.catena.2021.105199

22. Li C, Zwiers F, Zhang X, Chen G, Lu J, Li G, Norris J, Tan Y, Sun Y, Liu M (2019) Larger increases in more extreme local precipitation events as climate warms. Geophys Res Lett 46(12):6885-6891. https://doi.org/10.1029/2019GL082908

23. Li D, Gui Y, Li Y, Xiong L (2018) A method for constructing asymmetric pair-copula and its application. Communications in Statistics-Theory and Methods 47(17):4202-4214. https://doi.org/10.1080/03610926.2017.1371755

24. Li Y, Luo L, Chang J, Wang Y, Guo A, Fan J, Liu Q (2020) Hydrological drought evolution with a nonlinear joint index in regions with significant changes in underlying surface. J Hydrol 585:124794.

https://doi.org/10.1016/j.jhydrol.2020.124794

25. Lin X, Huang G, Piwowar JM, Zhou X, Zhai Y (2021) Risk of hydrological failure under the compound effects of instant flow and precipitation peaks under climate change: A case study of Mountain Island Dam, North Carolina. J Clean Prod 284:125305. https://doi.org/10.1016/j.jclepro.2020.125305

26. Liu Y, Li Y, Ma Y, Jia Q, Su Y (2020) Development of a Bayesian-copula-based frequency analysis method for hydrological risk assessment-The Naryn River in Central Asia. J Hydrol 580:124349.

https://doi.org/10.1016/j.jhydrol.2019.124349

27. Meaurio M, Zabaleta A, Boithias L, Epelde AM, Sauvage S, Sanchez-Perez JM, Srinivasan R, Antiguedad I (2017)

Assessing the hydrological response from an ensemble of cmip 5 climate projections in the transition zone of the atlantic region (bay of biscay). J Hydrol 548:46-62. https://doi.org/10.1016/j.jhydrol.2017.02.029

28. Motovilov YG, Gottschalk L, Engeland K, Rodhe A (1999) Validation of a distributed hydrological model against spatial observations. Agric For Meteorol 98:257-277. https://doi.org/10.1016/S0168-1923(99)00102-1

29. Muñoz DF, Moftakhari H, Moradkhani H (2020) Compound effects of flood drivers and wetland elevation correction on coastal flood hazard assessment. Water Resources Research. 56(7), e2020WR027544. 
https://doi.org/10.1029/2020WR027544

30. Nathan RJ, McMahon TA, Peel MC, Horne A (2019) Assessing the degree of hydrologic stress due to climate change. Clim Change 156(1-2):87-104. https://doi.org/10.1007/s10584-019-02497-4

31. Nelsen RB (2006) An introduction to copulas, 2nd edn. Springer-Verlag, New York

32. Nilawar AP, Waikar ML (2019) Impacts of climate change on streamflow and sediment concentration under RCP 4.5 and 8.5: A case study in Purna river basin, India. Sci Total Environ 650:2685-2696.

https://doi.org/10.1016/j.scitotenv.2018.09.334

33. Niu Z, Feng L, Chen X, Yi X (2021) Evaluation and Future Projection of Extreme Climate Events in the Yellow River Basin and Yangtze River Basin in China Using Ensembled CMIP5 Models Data. Int J Environ Res Public Health 18(11):6029. https://doi.org/10.3390/ijerph18116029

34. Paparrizos S, Maris F, Matzarakis A (2015) Integrated analysis of present and future response of precipitation over selected Greek areas with different climate conditions. Atmos Res 169:199-208.

https://doi.org/10.1016/j.atmosres.2015.10.004

35. Pastén-Zapata E, Jones JM, Moggridge H, Widmann M (2020) Evaluation of the performance of Euro-CORDEX regional climate models for assessing hydrological climate change impacts in Great Britain: a comparison of different spatial resolutions and quantile mapping bias correction methods. J Hydrol 584:124653.

https://doi.org/10.1016/j.jhydrol.2020.124653

36. Sadegh M, Moftakhari H, Gupta HV, Ragno E, Mazdiyasni O, Sanders B, Matthew R, AghaKouchak A (2018) Multihazard scenarios for analysis of compound extreme events. Geophys Res Lett 45(11):5470-5480.

https://doi.org/10.1029/2018GL077317

37. Sadegh M, Ragno E, Aghakouchak A (2017) Multivariate copula analysis toolbox (MvCAT): describing dependence and underlying uncertainty using a bayesian framework. Water Resour Res 53(6):5166-5183.

https://doi.org/10.1002/2016WR020242

38. Salvadori G, De Michele C (2007) On the use of copulas in hydrology:theory and practice. Journal of Hydrologic Engineering. 12(4), 369-380. https://doi.org/10.1061/(ASCE)1084-0699(2007)12:4(369)

39. Schwarz G (1978) Estimating the Dimension of a Model. The annals of statistics 6(2):461-464. http://www.jstor.org/stable/2958889

40. Shen $M$, Chen J, Zhuan M, Chen $H, X u$ C-Y, Xiong L (2018) Estimating uncertainty and its temporal variation related to global climate models in quantifying climate change impacts on hydrology. J Hydrol 556:10-24. https://doi.org/10.1016/j.jhydrol.2017.11.004

41. Sklar A (1959). "Fonctions de répartition à $n$ dimensions et leurs marges.. " Publ Inst Stat Univ Paris 8:229-231

42. Sorooshian S, Dracup JA (1980) Stochastic parameter estimation procedures for hydrologie rainfall-runoff models: Correlated and heteroscedastic error cases. Water Resour Res 16(2):430-442.

https://doi.org/10.1029/WR016i002p00430

43. Stott $P$ (2016) How climate change affects extreme weather events. Science 352(6293):1517-1518. https://doi.org/10.1126/science.aaf7271

44. Sun C, Huang G, Fan Y, Zhou X, Lu C, Wang X (2019) Drought occurring with hot extremes: Changes under future climate change on Loess Plateau. China. Earths Future 7(6):587-604. https://doi.org/10.1029/2018EF001103

45. Swain DL, Singh D, Touma D, Diffenbaugh NS (2020) Attributing extreme events to climate change: A new frontier in a warming world. One Earth 2(6):522-527. https://doi.org/10.1016/j.oneear.2020.05.011

46. Tofiq FA, Guven A (2015) Potential changes in inflow design flood under future climate projections for Darbandikhan Dam. J Hydrol 528:45-51. https://doi.org/10.1016/j.jhydrol.2015.06.023

47. Vinnarasi R, Dhanya CT (2019) Bringing realism into a dynamic copula-based non-stationary intensity-duration model. Adv Water Resour 130:325-338. https://doi.org/10.1016/j.advwatres.2019.06.009

Page $14 / 21$ 
48. Vormoor K, Lawrence D, Heistermann M, Bronstert A (2015) Climate change impacts on the seasonality and generation processes of floods - projections and uncertainties for catchments with mixed snowmelt/rainfall regimes. Hydrol Earth Syst Sci 19:913-931. https://doi.org/10.5194/hess-19-913-2015

49. Wang Q, Xu Y, Wang Y, Zhang Y, Xiang J, Xu Y, Wang J (2020) Individual and combined impacts of future land-use and climate conditions on extreme hydrological events in a representative basin of the Yangtze River Delta, China. Atmos Res 236:104805. https://doi.org/10.1016/j.atmosres.2019.104805

50. Wang Y, Xu Y, Lei C, Li G, Han L, Song S, Yang L, Deng X (2016) Spatio-temporal characteristics of precipitation and dryness/wetness in Yangtze River Delta, eastern China, during 1960-2012. Atmos Res 172:196-205.

https://doi.org/10.1016/j.atmosres.2016.01.008

51. Wilby RL, Dawson CW (2007) SDSM 4.2- A Decision Support Tool for the Assessment of Regional Climate Change Impacts.User Manual.94(1)

52. Wilby RL, Dawson CW, Barrow EM (2002) SDSM - a decision support tool for the assessment of regional climate change impacts. Environ Model Softw 17(2):145-157. https://doi.org/10.1016/S1364-8152(01)00060-3

53. Willmott CJ, Ackleson SG, Davis RE, Feddema JJ, Klink KM, Legates DR, O'Donnell J, Rowe CM (1985) Statistics for the evaluation and comparison of models. Journal of Geophysical Research-Oceans 90(NC5):8995-9005.

https://doi.org/10.1029/JC090iC05p08995

54. Xu P, Wang D, Singh VP, Lu H, Wang Y, Wu J, Wang L, Liu J, Zhang J (2020) Multivariate hazard assessment for nonstationary seasonal flood extremes considering climate change. Journal of Geophysical Research: Atmospheres. 125(18), e2020JD032780. https://doi.org/10.1029/2020JD032780

55. Yang X, Yu X, Wang Y, Liu Y, Zhang M, Ren L, Yuan F, Jiang S (2019) Estimating the response of hydrological regimes to future projections of precipitation and temperature over the upper Yangtze River. Atmos Res 230:104627. https://doi.org/10.1016/j.atmosres.2019.104627

56. Yin J, Guo S, He S, Guo J, Hong X, Liu Z (2018) A copula-based analysis of projected climate changes to bivariate flood quantiles. J Hydrol 566:23-42. https://doi.org/10.1016/j.jhydrol.2018.08.053

57. Yu KX, Zhang X, Li P, Li Z, Qin Y, Sun Q (2019) Probability prediction of peak break-up water level through vine copulas. Hydrol Process 33(6):962-977. https://doi.org/10.1002/hyp.13377

58. Zhang L, Singh VP (2007) Bivariate rainfall frequency distributions using Archimedean copulas. J Hydrol 332:93-109. https://doi.org/10.1016/j.jhydrol.2006.06.033

59. Zhang X, Hoermann G, Gao J, Fohrer N (2011) Structural uncertainty assessment in a discharge simulation model. Hydrological Sciences Journal 56(5):854-869. https://doi.org/10.1080/02626667.2011.587426

60. Zhang YQ, You QL, Chen CC, Ge J (2016) Impacts of climate change on streamflows under RCP scenarios: A case study in Xin River Basin, China. Atmos Res 178:521-534. https://doi.org/10.1016/j.atmosres.2016.04.018

61. Zhao G, Hoermann G, Fohrer N, Li H, Gao J, Tian K (2011) Development and application of a nitrogen simulation model in a data scarce catchment in South China. Agriculture Water Management 98:619-631.

https://doi.org/10.1016/j.agwat.2010.10.022

62. Zhu X, Ji Z, Wen X, Lee SY, Wei Z, Zheng Z, Dong W (2021) Historical and projected climate change over three major river basins in China from Fifth and Sixth Coupled Model Intercomparison Project models. Int J Climatol.

https://doi.org/10.1002/joc.7206

\section{Figures}



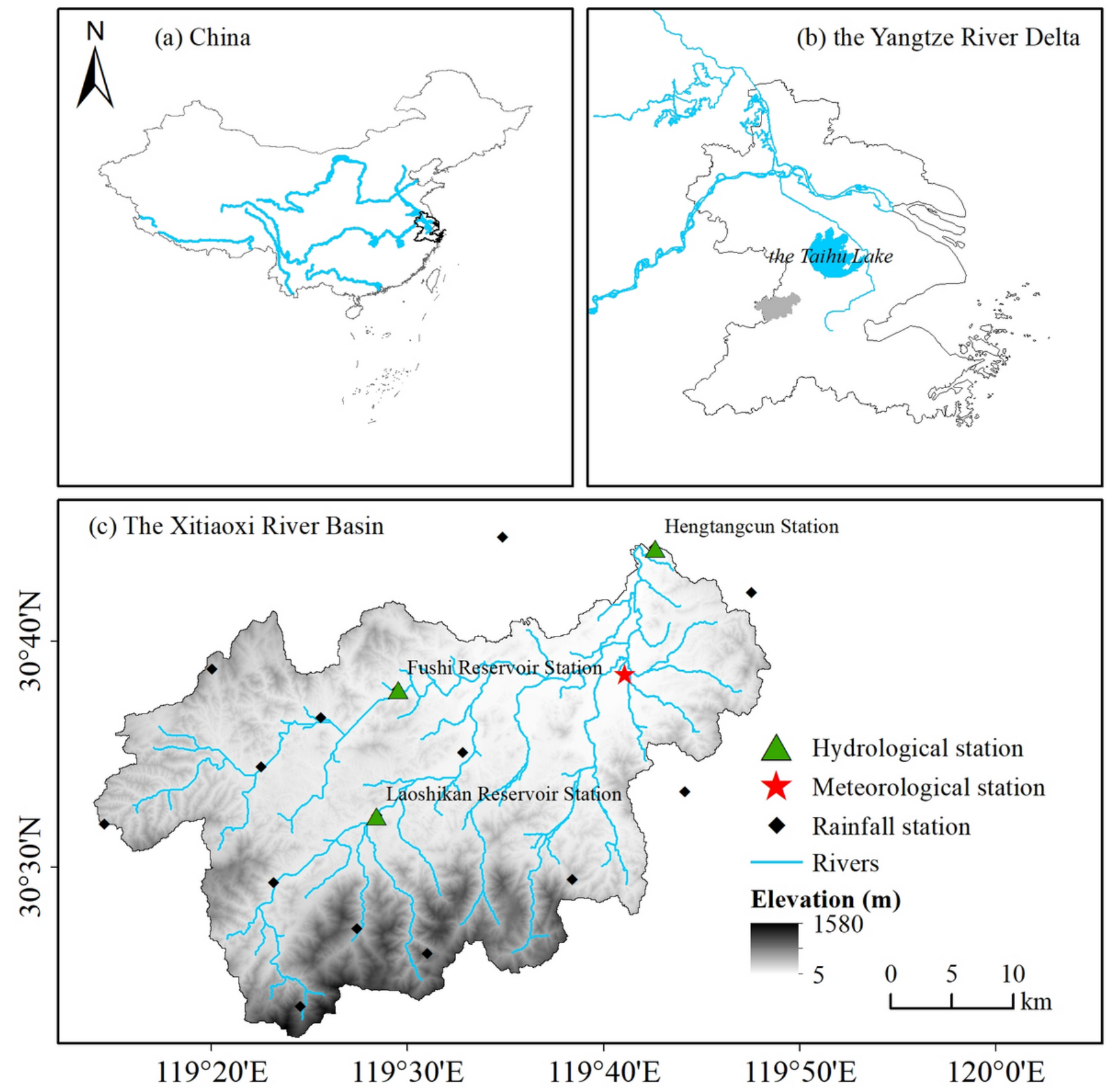

Figure 1

Study area and the distributions of rainfall stations 


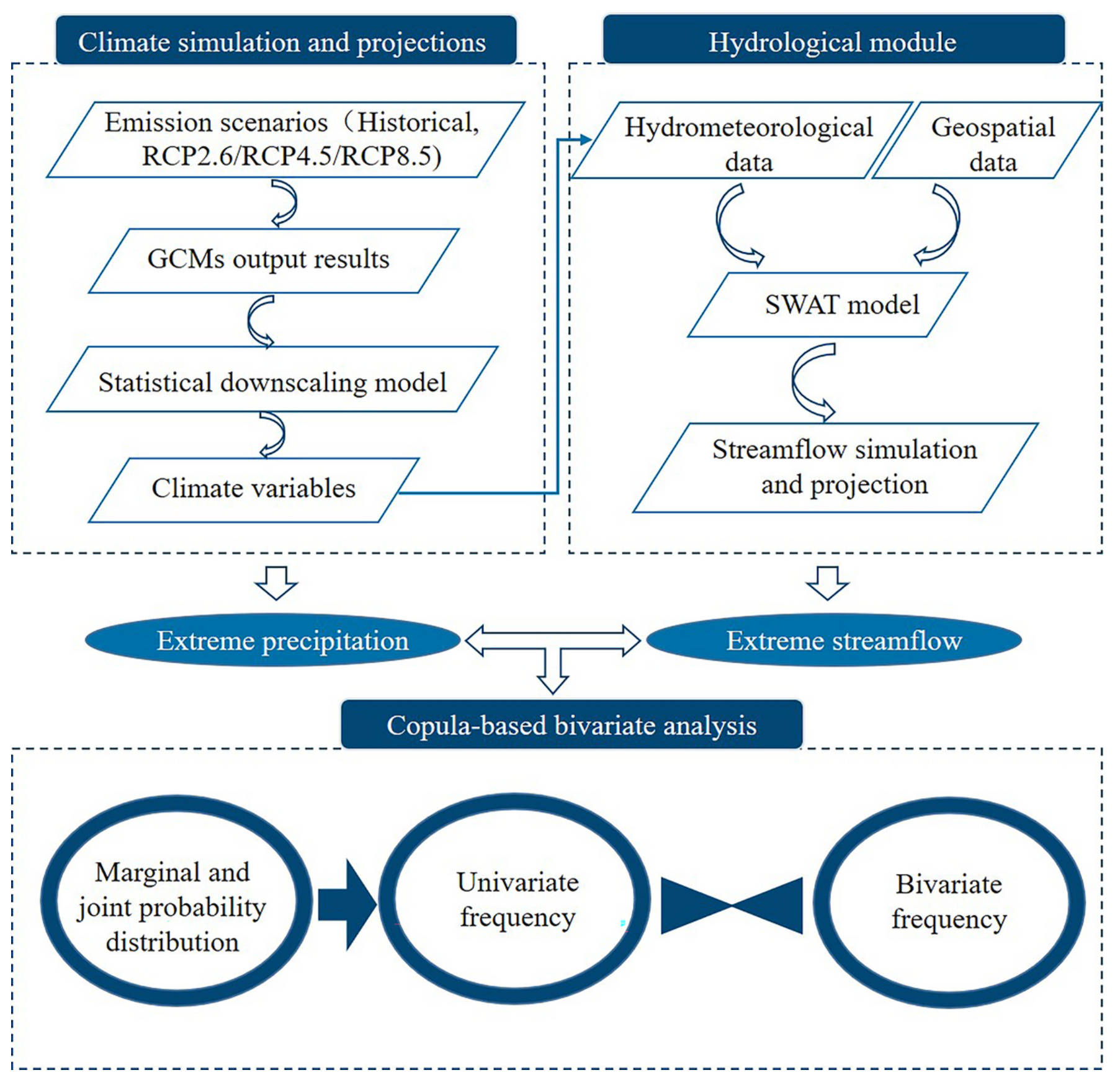

Figure 2

Methodology framework 

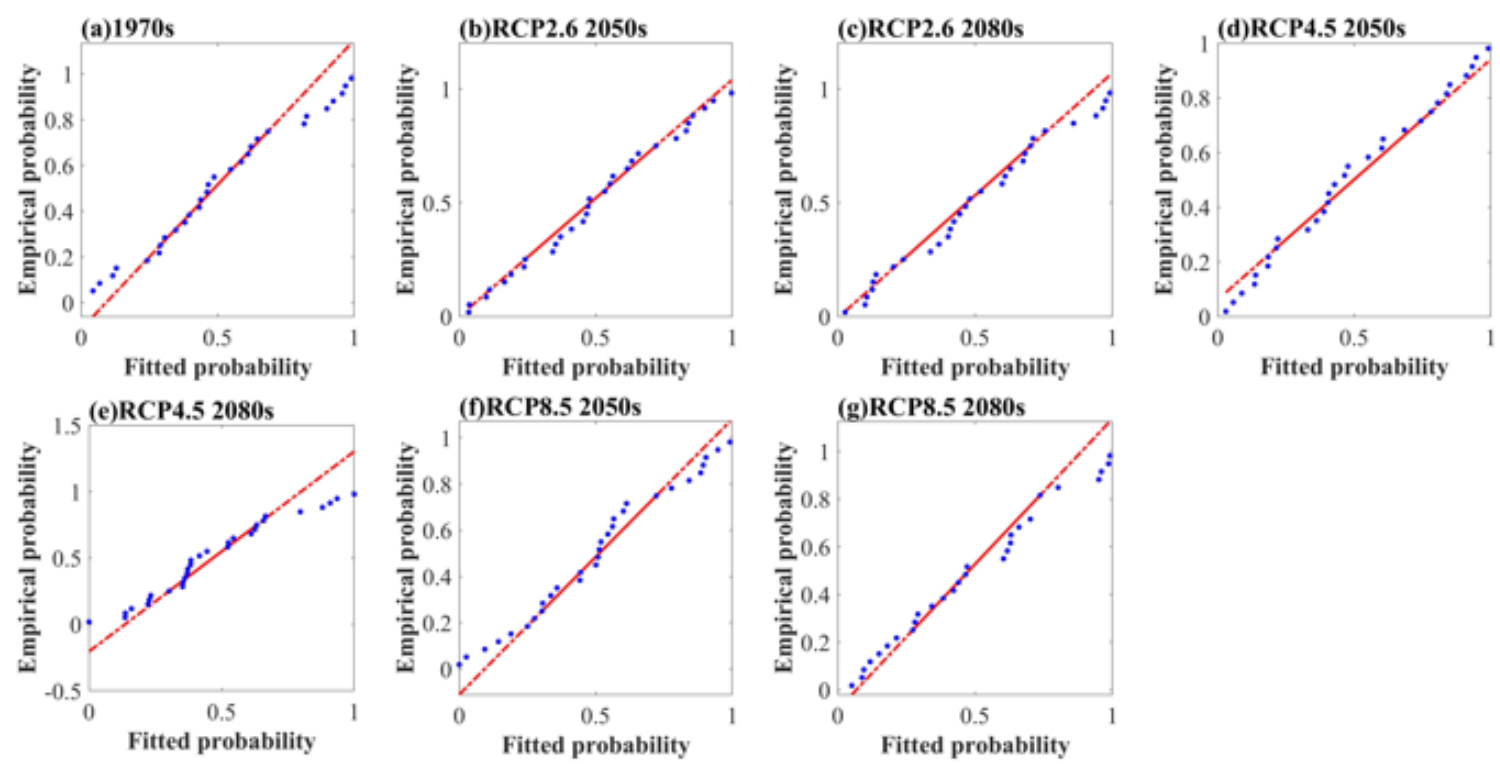

Figure 3

The Quantile-Quantile(Q-Q) plot of Rx1day under various climate scenarios
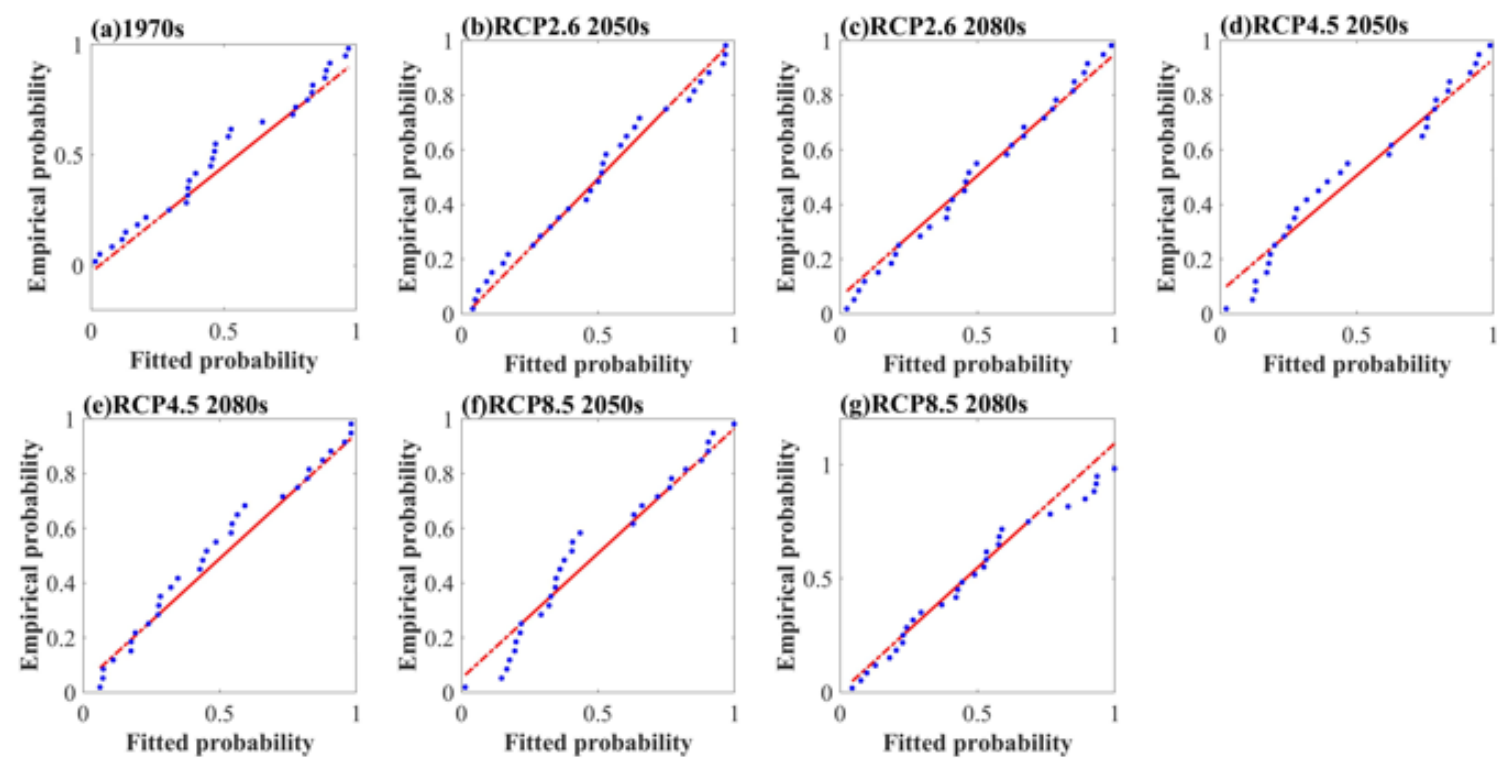

\section{Figure 4}

The Quantile-Quantile(Q-Q) plot of Sx1day under various climate scenarios. 

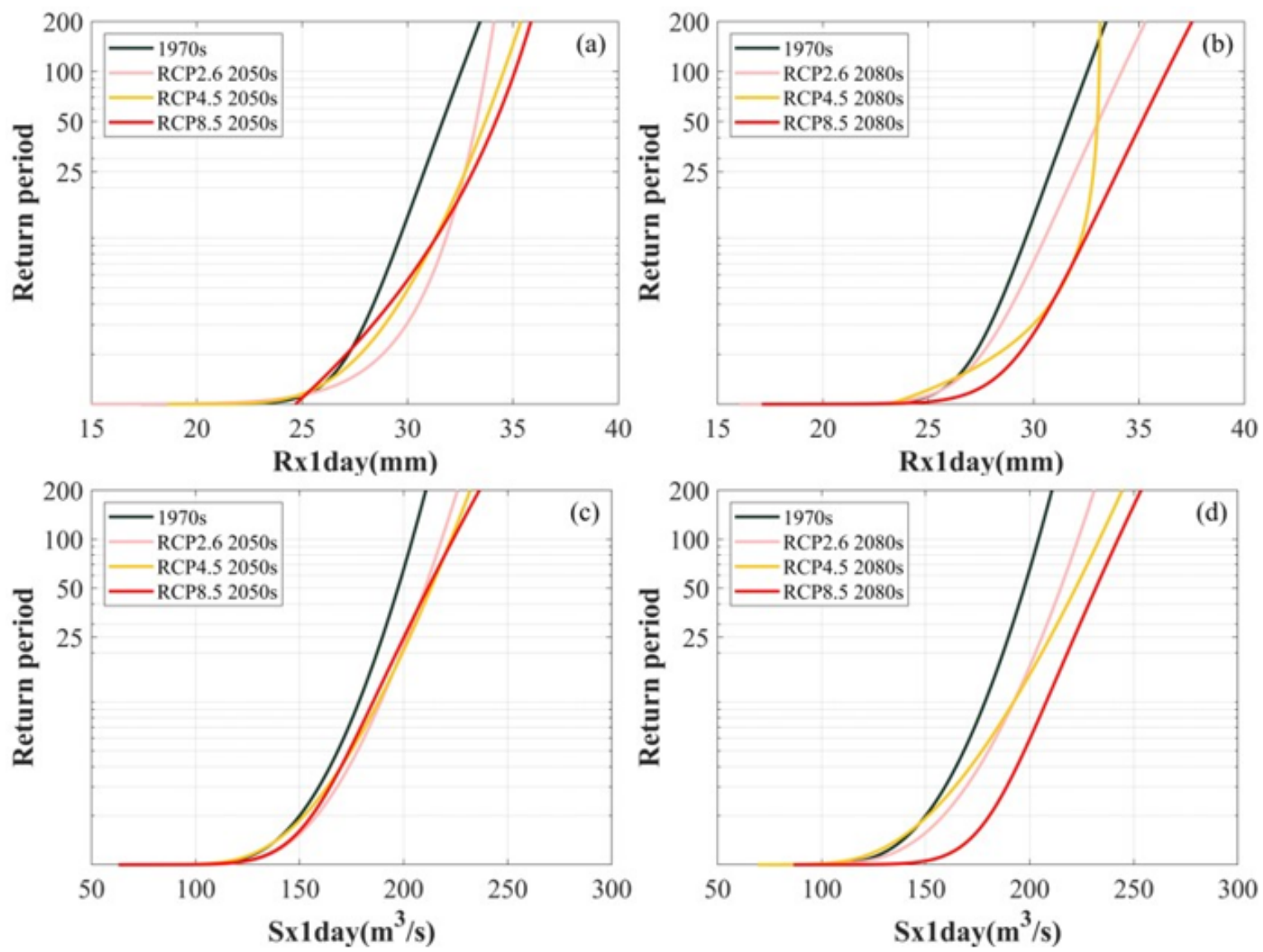

\section{Figure 5}

Marginal return period curves of Rx1day and Sx1day under different climate scenarios. 

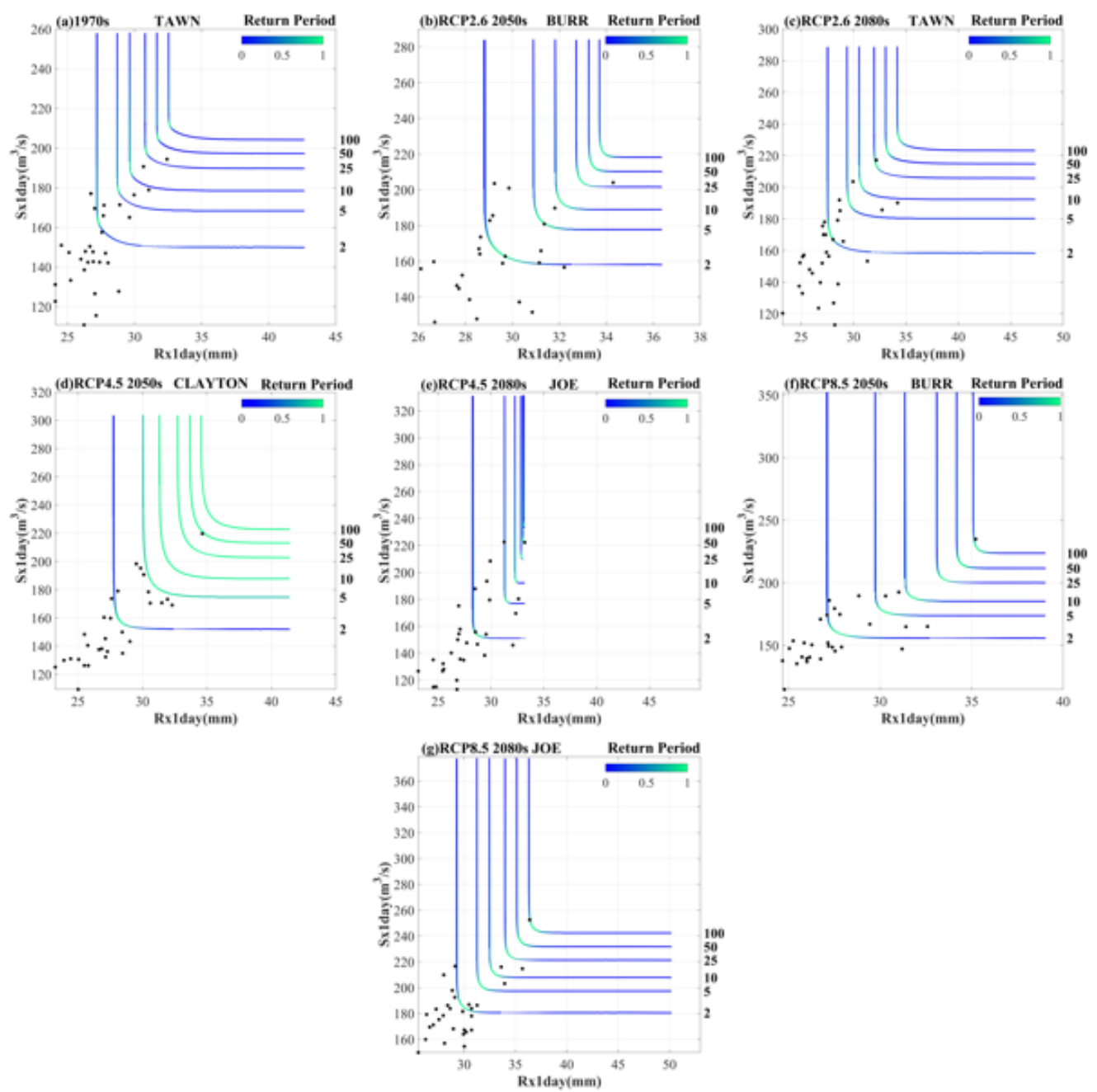

\section{Figure 6}

Joint return period isolines of Rx1day and Sx1day under different climate scenarios. Joint return period curves are color coded with probability densities, blue color representing lower densities and green representing higher densities. 

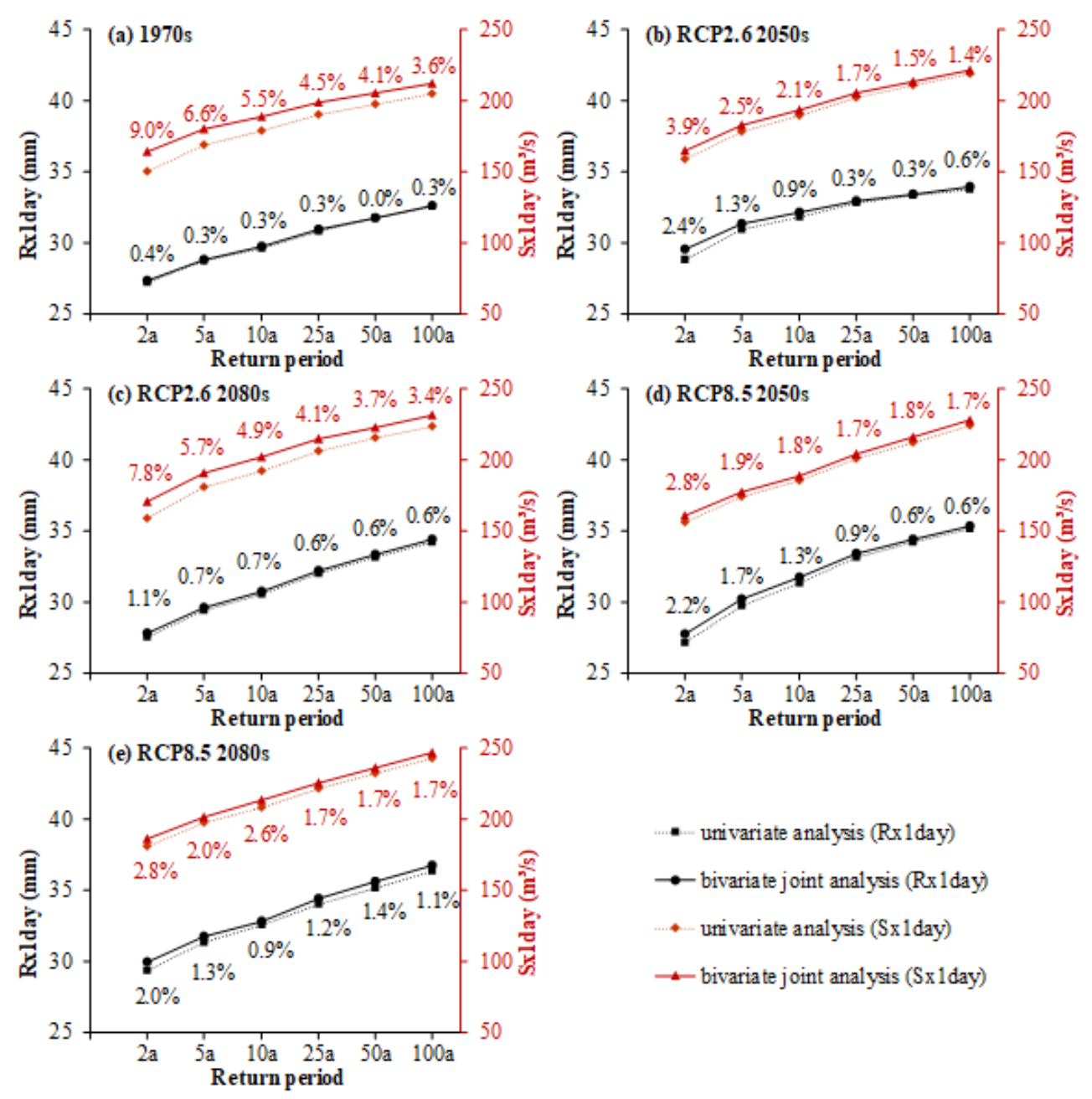

-.. univariate analysis ( $\mathrm{Rx} 1$ day)

$\rightarrow$ bivariate joint analysis (Rx 1day)

-.-univariate analysis ( $\mathrm{Sx} 1$ day)

$\multimap$ bivariate joint analysis (Sx 1 day)

Figure 7

Comparison between changes of Rx1day and Sx1day under univariate and bivariate joint analysis (Percentages are variations of bivariate analysis compared to univariate analysis.) 